\title{
ABSENTEÍSMO ENTRE OS TRABALHADORES DA ENFERMAGEM: CAUSAS E CONSEQUÊNCIAS
}

\author{
Sheila do Espírito Santo ${ }^{1}$ \\ Márcio Antônio de Assis ${ }^{2}$
}

RESUMO: O absenteísmo é um fenômeno caracterizado pela ausência do trabalhador no ambiente laboral. No contexto dos profissionais de enfermagem, essa circunstância se verifica de forma acentuada, influenciando significativamente no desempenho profissional e pessoal entre os trabalhadores. Assim, o principal objetivo do presente trabalho é identificar os motivos causais que levam os profissionais da aréa de enfermagem a se ausentarem do emprego, considerando fatores institucionais, vinculados a equipe de trabalho ou liderança e os intrínsecos ao próprio funcionário. De igual modo, intenta-se abordar as consequências geradas pelo absenteísmo para esses trabalhadores. Para tanto, a pesquisa esta fundamentada na revisão de literatura, especificamente a revisão integrativa, ora norteada pelas etapas de extração de dados, seleção de amostra, avaliação dos estudos, síntese dos resultados encontrados e apresentação, com base nas publicações relativas ao tema e indexadas nos bancos de dados da Literatura Latino-Americana em Ciências de Saúde (LILACS), e no Scientific Eletronic Library Online (SCIELO). Dessa forma, objetivando a sistematização e entendimento do tema que o estudo possa viabilizar a consolidação de ações futuras, voltadas ao resguardo da saúde dos trabalhadores e melhoramento da qualidade do atendimento e assistência prestados por eles no sistema de saúde.

Palavras-chaves: Absenteísmo. Enfermagem do trabalho. Saúde do Trabalhador. Profissionais de Enfermagem.

ABSTRACT: Absenteeism is a phenomenon characterized by the absence of the worker in the work environment. In the context of nursing professionals, this circumstance is strongly verified, significantly influencing professional and personal performance among workers. Thus, the main objective of this study is to identify the causal reasons that lead nursing professionals to leave their jobs, considering institutional factors, linked to the work team or leadership and those intrinsic to the employee. Likewise, it is intended to address the consequences generated by absenteeism for these workers. Therefore, the research is based on the literature review, specifically the integrative review, now guided by the steps of data extraction, sample selection, evaluation of studies, synthesis of the results found and

\footnotetext{
' Acadêmica de Enfermagem na Universidade de Mogi das Cruzes - UMC. E-mail: Sheila.es@hotmail.com ${ }^{2}$ Enfermagem pelo Centro Universitário Nove de Julho. Mestrado e Doutorado em Engenharia Biomédica pela Universidade de Mogi das Cruzes. Pós-doutorado em Enfermagem pela Universidade Estadual Paulista. Júlio de Mesquita Filho UNESP Botucatu.
} 


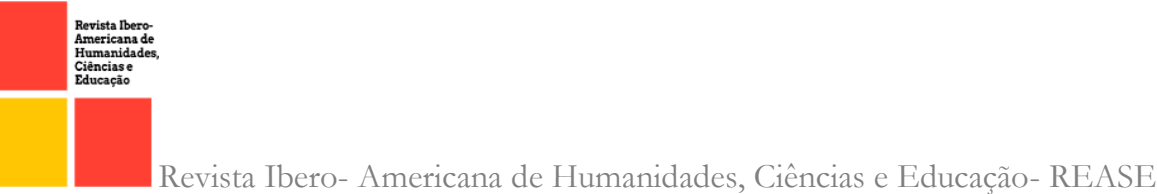

presentation, based on publications related to the topic and indexed in the databases of the Latin American Literature in Health Sciences (LILACS), and in the Scientific Electronic Library Online (SCIELO). Thus, aiming at the systematization and understanding of the theme, the study can enable the consolidation of future actions, aimed at safeguarding the health of workers and improving the quality of care and assistance provided by them in the health system.

Keywords: Absenteeism. Nursing work. Worker's health. Nursing professionals.

\section{INTRODUÇÃO}

O trabalho é uma atividade indispensável para o desenvolvimento individual e coletivo das pessoas, funcionando como um dos meios para a aquisição de identidade, de status, e uma das principais fontes de satisfação das necessidades humanas (LUCCA E RODRIGUES, 2015).

Nesse sentido, quando desprovido da valoração as necessidades e anseios profissionais, o ambiente laboral pode culminar no desgaste da saúde dos trabalhadores, logo, causando um mal-estar. Assim, Dejours (2012) preconiza que as atividades desempenhadas no trabalho pode impulsionar o colaborador ao seu melhor potencial, todavia, pode também, resultar no seu pior e ocasionar doenças.

Em relação a isso, Murcho e Murcho (2014) falam que a aparição de doenças pode estar associada ao mal-estar ocupacional, que, por conseguinte, se manifesta de diferentes formas, agrupando-se em sintomas físicos, cognitivos, emocionais e comportamentais. Instante em que pode advir o absenteísmo.

O absenteísmo é definido como a ausência profissional do emprego. Trata-se do tempo de labor perdido quando o contratado não compareceu ao trabalho e, corresponde as ausências quando se esperava que ele estivesse presente, não justificado por falta ou atraso (MURCHO E JESUS, 2014).

Em consonância com o supracitado, Chiavenato (2014) reforça que o absenteísmo pode ser entendido como a falta do trabalhador em seu ambiente de trabalho, quando ele deveria estar presente, salientando que há múltiplas motivações capazes de provocar sua ocorrência. 
O fenômeno é classificado em quatro tipos. O primeiro é chamado como absenteísmo voluntário, provocado por motivos particulares dos profissionais, sem uma justificativa prévia e formal diante da organização em que está inserido. O segundo dar-se por doença, sendo elas patologias ou procedimentos médicos, excluindo-se os relacionados ao trabalho. O terceiro tipo é derivado dos acidentes ou doenças trabalhistas e o último é motivado por sanções disciplinares ou prisão do trabalhador (MURCHO E JESUS 2014).

Neste sentido, a análise da temática vigora como um importante indicador do estado de saúde de determinado grupo de trabalhadores, como também pode indicar condições de trabalho inadequadas que necessitam ser ajustadas para melhorar as condições laborais dos indivíduos (AZEVEDO et al. 2019).

No âmbito hospitalar, os profissionais de enfermagem atuam exaustivamente, inclusive com extensivas jornadas de trabalho. Assim, se considera o serviço de um enfermeiro essencial e exigente. Isso porque os profissionais frequentemente lidam com o atendimento das demandas sociais, quais sejam as de enfermidades físicas da coletividade, residindo aí a importância de se também primar pelo bem-estar e saúde - física e mental, desse grupo (BRITO, SOUZA E RODRIGUES, 2019, p. I13-122).

Importante mencionar ainda que segundo o Conselho Federal de Enfermagem COFEN (1986) são considerados profissionais de enfermagem os enfermeiros, os técnicos, auxiliares de Enfermagem e a parteira.

Outrossim, esses profissionais estão expostos aos diversos estressores ocupacionais que afetam a sua saúde. São fatores que geram a constante exaustão emocional e estão relacionados aos fatores individuais, organizacional e do ambiente de trabalho. Tais como as longas jornadas de trabalho, número insuficiente de pessoal, a falta de reconhecimento profissional, a exposição do profissional a riscos biológicos, químicos, ergonômicos, etc (UMANN, 20II; SOBRAL, 2015).

A falta de correspondência com as exigências da classe também impõe o sentimento de insatisfação. Sobre isso, UMANN (20II) expõe que o "impacto do trabalho aos profissionais pode desencadear ansiedade, estresse, tensão e, consequentemente, ausências 
não justificadas ou justificadas por licenças médicas, denominadas de absenteísmo”. Assim, perfaz necessário proceder intervenções preventivas visando a redução das repercussões negativas causadas pelo absenteísmo, com isso reconhecendo fatores determinantes a sua ocorrência, as consequências que afligem os próprios profissionais, as organizações e assistência aos pacientes.

Desse modo, o presente estudo intenta esclarecer "Quais as causas e as consequências geradas pelo comportamento absenteísta dos profissionais de enfermagem?”. Pretendendo que o entendimento acerca do absenteísmo e reconhecimento das causas e as consequências geradas pelo fenômeno no contexto dos profissionais de enfermagem, possa subsidiar a consolidação de ações pautadas no amparo e resguardo da saúde dos trabalhadores, tal como propiciar a qualidade do atendimento prestados por eles no sistema de saúde.

\section{METODOLOGIA}

Este estudo foi realizado por intermédio de uma revisão de literatura, especificamente a integrativa. Assim, revisão integrativa é o método usado para analisar e sintetizar pesquisas, contribuindo para responder questões norteadoras e o aprofundamento da temática, assim como para a síntese de um conhecimento através de um processo sistemático e rigoroso (MENDES, 2019). Por conseguinte, tendo também como base a pesquisa descritiva.

Para tanto, a condução do estudo foi norteada pelas seguidas etapas: identificação do tema e seleção da questão da pesquisa; extração dos dados de estudos; estabelecimento de critérios para inclusão e exclusão de estudos (seleção de amostra); avaliação crítica dos estudos incluídos; síntese dos resultados; e apresentação dos resultados e discussão (MENDES, 2019)

A extração de dados foi realizada por intermédio de consultas feitas nos bancos de dados bibliográficos da Biblioteca Virtual em Saúde (BVS) com repositórios nas bases de dados da Literatura Latino-Americana em Ciências de Saúde (LILACS) e Scientific Eletronic Library Online (SCIELO). Nesse momento, serão utilizados os seguintes descritores: "Absenteísmo", "Enfermagem do trabalho", "Saúde do Trabalhador" e "Profissionais de Enfermagem”, todos validados pelos Descritores de Ciência em Saúde (DECs) e compostos pelo conectivo booleano “AND”, visando o filtro e a delimitação dos 
resultados a serem encontrados.

Depois da busca através dos descritores, aplicou os critérios de inclusão, englobando estudos primários indexados nas bases de dados do ano de 2010 até 2020, desde que publicados na integra, e em língua portuguesa, envolvendo os artigos que disponham especificamente do absenteísmo na enfermagem do trabalho; o absenteísmo na saúde do trabalhador; o absenteísmo exclusivamente entre profissionais de enfermagem e correlatos. Retirando, através dos critérios de exclusão, os artigos em línguas estrangeiras, aqueles não disponibilizados na integra e os que não abrangem a temática.

Sendo, posteriormente, selecionados através de uma leitura minuciosa dos resultados e títulos, aqueles que tem correspondência com o objetivo pretendido pelo trabalho. De modo que depois de realizada a seleção dos títulos, procedeu-se também à leitura dos resumos e, da mesma forma, analisando-se se possuíam alguma relação com a temática.

Com isso, as publicações que tenham os títulos e resumos relacionados com a pesquisa foram inseridas em pastas do Windows para fins de organização. De modo que nessa etapa foi feita outra leitura, só que dessa vez, do texto integral para então verificar se estão atrelados com a questão norteadora do trabalho ou não, cujo o total de produções encontradas foram utilizadas no desenvolvimento da pesquisa.

Por fim, objetivando a identificação e descrição das causas associadas ao absenteísmo entre os trabalhadores de enfermagem, sua associação com os fatores institucionais, intrínsecos ao colaborador, vinculados a equipe ou liderança, e as consequências geradas pelo fenômeno no âmbito pessoal e organizacional em que o profissional está inserido.

\section{RESULTADOS E DISCUSSÕES}

O estudo foi conduzido com base no método da revisão de literatura, especificamente a revisão integrativa. Nesse contexto, foram realizadas pesquisas nas bases de dados do LILACS e SCIELO, buscado selecionar as publicações que mais tinham relação com a temática proposta. Em decorrência disso, foram encontrados o total de 189 artigos, dentre os quais somente 2I foram inseridos para compor o trabalho, representando a quantificação de II,I\%. Da aplicação das etapas ilustradas no método adveio os seguintes resultados: 
Tabela or - Distribuição dos artigos disponíveis no LILACS (2010-2020) relativo ao objeto de estudo do presente trabalho.

\begin{tabular}{|c|c|c|c|c|c|c|}
\hline BASE DE DADOS & ANO & ENCONTRADOS & TITULO & RESUMO & INTEGRA & INSERIDOS \\
\hline LILACS & 2010 & 15 & 6 & 4 & 2 & 2 \\
\hline LILACS & 2011 & II & 8 & 6 & 5 & 3 \\
\hline LILACS & 2012 & I6 & 5 & 2 & 2 & I \\
\hline LILACS & 2013 & Io & 4 & 3 & 2 & o \\
\hline LILACS & 2014 & I6 & 7 & 5 & 5 & 2 \\
\hline LILACS & 2015 & II & 6 & 5 & 3 & 2 \\
\hline LILACS & 2016 & Io & 5 & 3 & 3 & I \\
\hline LILACS & 2017 & 8 & 4 & 4 & 3 & I \\
\hline LILACS & 2018 & 22 & 6 & 3 & 3 & 2 \\
\hline LILACS & 2019 & 27 & 5 & 3 & 2 & o \\
\hline LILACS & 2020 & Iо & 4 & 2 & 2 & I \\
\hline LILACS & $2010-2020$ & 156 & 60 & 40 & $3 \mathrm{I}$ & 15 \\
\hline
\end{tabular}

Tabela 02 - Distribuição dos artigos disponíveis no SCIELO (2010-2020) relativo ao também objeto de estudo do presente trabalho.

\begin{tabular}{|c|c|c|c|c|c|c|}
\hline BASE DE DADOS & ANO & ENCONTRADOS & TITULO & RESUMO & INTEGRA & INSERIDOS \\
\hline SCIELO & 2010 & 2 & I & I & I & o \\
\hline SCIELO & 2011 & 4 & 2 & 2 & 2 & o \\
\hline SCIELO & 2012 & 3 & 2 & 2 & 2 & I \\
\hline SCIELO & 2013 & 2 & I & I & I & I \\
\hline SCIELO & 2014 & 3 & 2 & 2 & 2 & I \\
\hline SCIELO & 2015 & 4 & 2 & 2 & 2 & I \\
\hline SCIELO & 2016 & 3 & I & I & I & I \\
\hline SCIELO & 2017 & 2 & o & o & o & o \\
\hline SCIELO & 2018 & 4 & 2 & 2 & 2 & o \\
\hline SCIELO & 2019 & 4 & 2 & 2 & 2 & I \\
\hline SCIELO & 2020 & 2 & I & I & I & o \\
\hline SCIELO & $2010-2020$ & 33 & 16 & 16 & 16 & 6 \\
\hline
\end{tabular}

Assim, o desenvolvimento dos resultados e discussões serão divididos em duas partes. A primeira se propõe a demonstrar as causas do absenteísmo entre profissionais de 
enfermagem através da separação, meramente didática, em fatores institucionais, relativos à equipe ou liderança e os associados ao próprio profissional que, por sua vez, contribuem para a ocorrência do fenômeno no âmbito da enfermagem. Igualmente, a segunda parte tem como objetivo narrar as consequências advindas do absenteísmo para esses mesmos profissionais. Assim, visando o entendimento acerca da temática e a colaboração para a proposição de futuras estratégias por parte de outros estudiosos após a identificação da problemática, buscando ações afirmativas para um melhor amparo e resguardo da saúde desses trabalhadores e a melhora da qualidade do atendimento prestados por eles no sistema de saúde.

\section{CAUSAS DO ABSENTEÍSMO ENTRE PROFISSIONAIS DE ENFERMAGEM}

A etiologia - ciência que busca determinar as causas existenciais, do absenteísmo tem um caráter multifatorial. Isso quer dizer que, decorrente de sua complexidade, o fenômeno pode ter inúmeros agentes motivadores. Esses, por vezes, estão relacionados entre si e podem potencializar a experiência de sofrimento por parte dos trabalhadores durante a prática laboral e revelar-se como uma situação de difícil resolução, especialmente quando no contexto das organizações de saúde (SANCINETTI, et al. 20II; SILVA et al. 2018; PIMENTA, et al. 2020).

Nesse sentido, compreendeu-se pelo aparato bibliográfico de forma enfática que as causas do absenteísmo nem sempre se restringem ao colaborador e sua voluntariedade, mas sofrem pela ação ou omissão da organização como um todo. Notou-se, no último caso, que a formação de ambientes laborais desmotivadores, insalubres e desfavoráveis à execução da atividade proporcionam uma queda de produtividade e a elevação dos índices de afastamentos, dada as diversas reações do corpo humano ao trabalho pela dor, adoecimento, desgaste, sofrimento mental e físico (MININEL, et al. 2013; PORTO, 2016).

Não obstante, a ausência profissional abrangida por questões da própria organização e a equipe de enfermagem, pode ser dar pela insuficiência de recursos humanos, repetitividade das atividades, excesso de trabalho, treinamento insuficiente, relações tensas 


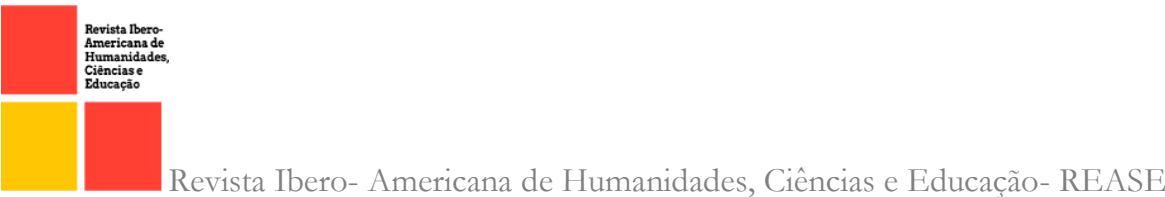

na equipe, e integração precária entre os profissionais e a organização (SANCINETTI, et al. 20I1; LUCCA E RODRIGUES, 2015).

Assim, o que gera adoecimento aos profissionais de enfermagem estão principalmente relacionadas às condições de trabalho ou fatores organizacionais, cujas consequências estão vinculadas ao grande desgaste físico e mental (REZENDE, BORGES E FROTA, 2012).

Neste contexto, os motivos para o absenteísmo na enfermagem pode estar relacionado com os aspectos organizacionais (falta de materiais e equipamentos adequados, doenças ocupacionais), de liderança ou equipe (longas jornadas de trabalho, baixa remuneração, número insuficiente de profissionais, conflitos nas relações interpessoais), pessoais (motivos familiares, acompanhamento de filhos, doença ocorridas fora do ambiente de trabalho etc.)

\section{ASSOCIADO AO AMBIENTE INSTITUCIONAL}

Segundo Porto (2016) o absenteísmo é considerado como um problema socioeconômico que as organizações em todos os países enfrentam, resultando em perdas da produtividade. Não só isso, salienta-se que o fenômeno gerado no ambiente institucional influência significativamente na qualidade da saúde do trabalhador e a assistência prestada.

No contexto da Enfermagem, observa-se um grupo de trabalhadores que se expõe, continuamente a riscos de natureza biológica, física e psicológica. Esse mesmo grupo é também responsável por realizar atividades comumente marcadas pela rígida hierarquia, pela divisão de tarefas, cumprimento de protocolos e pelo insuficiente dimensionamento de pessoal e recursos, fatores que podem provocar uma alta taxa de absenteísmo (UMANN, et al. 20II; SILVA, et al. 2018,)

Para tanto, o local onde desempenham suas atividades deveria considerar a oferta de uma estrutura física adequada, bons equipamentos e material de qualidade, tal como investimentos na área de recursos humanos que visem a satisfação dos profissionais, de modo a favorecer seu crescimento, participação na instituição e no processo de cuidar. (FERREIRA, et al. 20II; LUCCA E RODRIGUES, 2015; FERRO, et al. 2018). 
Todavia, quando essa oferta de subsídios adequados ao exercício da profissão e primazia pela saúde do trabalhador não ocorre, tem-se a precarização das condições laborais, tais como: estrutura física de trabalho precária ou não planejada, equipamentos escassos e que exigem muita manutenção e insumos de baixa qualidade e/ou insuficientes para atendimento das necessidades dos pacientes, que podem levar ao absenteísmo (FERRO, et al. 2018).

A partir do estudos coletados para compor o presente trabalho, entendeu-se que o próprio espaço ou instituição de trabalho podem ensejar no afastamento ou ausência do profissional. $\mathrm{Na}$ verdade, tem-se percebido que a realidade vivenciada por muitos trabalhadores da enfermagem vem acarretando em agravos à saúde, provenientes do ambiente laboral, da organização e das atividades insalubres executadas, o que causa prejuízo não só a eles, mas às instituições empregadoras e assistenciais em todo o mundo (CARVALHO, et al. 20I0).

Com isso, profissionais de enfermagem começam a apresentar, entre outros, transtornos da alimentação, do sono, a fadiga, o estresse, a diminuição do estado de alerta, a desorganização do núcleo familiar e neuroses, além de todo tipo de riscos (físicos, biológicos, ergonômicos, psicológicos e de acidentes de trabalho) (MARTINATO et al., 20Io).

Enquanto as condições precárias no ambiente laboral permanecem sendo consideradas frequentes e minam a saúde e qualidade de vida do profissional, gerando intenso sofrimento, elevação dos riscos ocupacionais, aumento no número de reações adversas e acidentes de trabalho (PIMENTA, et al. 2020).

Tais condições também implicam em longas jornadas, trabalho em turnos desgastantes, repetitividade e monotonia, ansiedade, esforços físicos, posições incômodas, que juntamente com o estresse, baixa remuneração, cansaço e a exaustão, aumentam os índices de absenteísmo (MAGALHÃES, et al. 20II). Outrossim, na presença de condições inadequadas, o profissional pode realizar seu trabalho de forma mecânica, sem tempo para desenvolver conhecimentos, suas competências e habilidades, tornando-se frustrado em relação a sua função. (REZENDE, BORGES E FROTA, 2012). 
Dito isso, é possível afirmar que as dinâmicas organizacionais geram uma sobrecarga de ação e tensão com proporções distintas a se considerar cada profissional e seu campo de atuação. Sendo que a maioria dos estudos consideraram que a exposição aos agentes estressores, dada a sobrecarga, a desorganização do serviço e instituição, a falta de suporte, o duplo vínculo de trabalho e a falta de apoio para o aprimoramento profissional acarretam na alta frequência de faltas ao trabalho e pedidos de licença, inclusive por doenças ocupacionais (REZENDE, BORGES E FROTA, 2012).

Martinato et al. (2010) preconiza que "a exposição contínua e prolongada do corpo aos fatores de risco, em um ambiente de trabalho inadequado, favorece o surgimento das doenças ocupacionais e osteomusculares".

Diante disso, destacou-se que entre os problemas de saúde que acometem os trabalhadores de enfermagem, estão as doenças osteomusculares e do tecido conjuntivo como as principais causa de licenças médicas (FERREIRA, et al. 2oII; MAGALHÃES, et al. 20II; REZENDE, BORGES E FROTA, 2012; LUCCA E RODRIGUES, 2015; MARQUES, et al. 2015; ROCHA, et al. 2019).

Neste contexto, a doença osteomuscular é identificada como um problema que aflige os profissionais de enfermagem e decorrem do risco ergonômico em que eles expostos diariamente no ambiente de trabalho (CARVALHO, et al. 2oro).

O desconforto/dor osteomuscular pode derivar de diversas situações que exigem grande esforço físico e psicológico, ultrapassando, muitas vezes, o limite da capacidade do trabalhador. Ao passo que o colaborador ao precisar se manter no mercado e garantir o emprego se submete às grandes exigências da instituição na qual se encontra (MARTINATO et al, 2oio).

Outrossim, os estudos indicaram que estão em segundo lugar como problemas de saúde e causa do absenteísmo, as doenças mentais e comportamentais (MAGALHÃES, et al. 20II). Em todos eles, destacou-se episódios depressivos, transtornos bipolares e estresse como motivos causais, sendo que esses adoecimentos podem ser ampliados pelo convívio constante do profissional de enfermagem com a dor, o sofrimento e a morte. Nesse sentido, 
Marque et al (2015) indica que essas condições podem fazer com que os profissionais desenvolvam doenças psiquiátricas.

Não obstante, observou grande incidência no número de profissionais de enfermagem sendo levado ao absenteísmo por ter sido acometido pela Síndrome de Burnout ou Síndrome do Esgotamento Profissional. Trata-se de distúrbio psíquico caracterizado por reação de tensão emocional crônica gerada pelo contato direto, excessivo e estressante no ambiente de trabalho, repercutindo na saúde física e mental do trabalhador. (REZENDE, BORGES E FROTA, 2012).

Através do estresse acentuado, geram-se sentimentos de desamparo que podem ocasionar ao profissional a concorrência para uma situação irremediável, prejudicando sua concentração, a vigilância e capacidade de supervisão (SANCINETTI et al. 20II; PERES, 2016). Segundo os artigos, o estresse no trabalho decorre da falta de autonomia para a tomada de decisões, da ausência de reconhecimento e excesso de responsabilidades, além do constante contato com o sofrimento e a monotonia gerada por um trabalho as vezes enfadonho e repetitivo. (FERREIRA, et al. 20I1; LUCCA E RODRIGUES, 2015; ROCHA, 2019).

Outrossim, dez dos artigos citaram as doenças infecciosas, infectocontagiosas e parasitárias; problemas cardiovasculares e respiratórios, alergias; os acidentes com exposição aos fluidos corpóreos e urna variada sintomatologia como fatores causais do absenteísmo (FERREIRA, et al. 20II).

Cumpre também mencionar que os profissionais mais expostos ao absenteísmodoença em ambientes hospitalares são a equipe de enfermagem, porém o predomínio de ausências ao trabalho se encontram na categoria dos auxiliares e técnicos de enfermagem. (LUCCA E RODRIGUES, 2015; SILVA et al. 2018; ROCHA, 2019).

Não obstante, atribui-se a maior ocorrência de faltas com base nas peculiaridades de certos setores, onde os trabalhadores estão mais expostos a transtornos de ordem física, química e psicológica, a exemplo dos caso das unidades de tratamento intensivo, ora especializadas no atendimentos de pacientes graves e alta complexidade (FERREIRA, et al. 2011; MARQUES et al. 2015; PERES, 2016). 
Assim evidenciando a essencialidade em promover a saúde do trabalhador por meio de condições adequadas de trabalhados, que incialmente poderão estar pautadas na oferta de programas assistenciais cujo investimento perpassa a área de recursos humanos e gestão de pessoas visando elencar quais as necessidades daqueles que integram a instituição hospitalar. (SILVA et al, 2018)

\section{ASSOCIADA A LIDERANÇA OU A EQUIPE DE TRABALHO}

As relações interpessoais são primordiais para o bom desenvolvimento do trabalho em equipe, especialmente no contexto de atuação dos profissionais de enfermagem. Neste sentido, boas interações além de garantir a eficiência do indivíduo, apresentam-se como uma forma de inserção social que favorece o relacionamento interpessoal, a motivação e satisfação com do exercício profissional. Cumprindo-se também como essencial na prevenção do adoecimento no trabalho (REZENDE, BORGES E FROTA, 2oır; FERRO, et al. 2018; PIMENTA, 2020).

Apesar disso, nove dos estudos mencionaram que os problemas relativos a liderança ou equipe são mais comuns e uma realidade a contribuir para o índice de absenteísmo. Entre as causas do absenteísmo nesse aspecto, permeiam os conflitos com os superiores hierárquicos, insatisfação com a organização dos serviços e a desvalorização causada por baixa remuneração. Esse conflitos com a equipe de trabalho demonstram relação com a deficiência na liderança, assim, gerando descontentamento ao profissional, o que veem a ocasionar o absenteísmo (KURCGANT, et al. 2015; SILVA, et al. 2018).

Também a ausência ou deficiência na comunicação pode gerar clima desfavorável entre a equipe e consequentemente levar os profissionais ao absenteísmo, em função da desmotivação relacionada ao processo de trabalho (FERRO, et al. 2018).

Sobre isso, os achados frisaram a importância do estabelecimento de diálogos como condutores na relação entre superior e subordinado, visando o esclarecimento do motivo da falta e as conversas informais para haja melhor relacionamento pessoal e profissional.

Também em relação a isso, observou-se que a dificuldade de comunicação como um dos fatores motivadores de conflitos e, por conseguinte, do absenteísmo foi apontada como 
essencial a ser melhorada para o desenvolvimento do trabalho em equipe. Igualmente, em um dos estudos evidenciou-se que a comunicação ao surtir efeito no processo de relação interpessoal, acaba por contribuir para o cuidar, possibilitando a criação de vínculo entre o usuário e o serviço. (BREY, 2017; SILVA, et al, 2018).

Como ponto de resolução, foi abordado em um dos artigos, a ação das enfermeiras gerentes de realizar reuniões com o demais profissionais com o objetivo de serem destacados a importância da colaboração mutua e ajuda na solução de problemas pessoais, mantendo sempre os canais de comunicação abertos (KURCGANT, et al. 2015).

Outrossim os estudos colocaram a ausência de um plano de carreira e baixa remuneração como também potenciais geradores de absenteísmo entre a equipe de enfermagem. Tal como a ambiguidades de papéis e acúmulo no desempenho das atividades. Sobre isso, autores ressaltam a importância da remuneração na motivação das pessoas e para o desempenho no trabalho, de modo que uma melhor remuneração pode fazer com que o trabalhador desempenhe melhor sua função, bem como servir como incentivo, visando atingir ou superar as metas propostas pelas organizações. (FERRO, et al. 2018).

Com isso, o aspecto remuneratório torna-se fator motivador no desempenho do trabalho realizado, sendo fundamental que os serviços disponham de políticas de planos de cargos e salários estruturados, uma vez que a ausência interfere negativamente na eficiência e eficácia das atividades desenvolvidas. Também observou-se que as queixas do profissionais estão em salários defasados e que não atendem as demandas laborais.

Essa última situação pode influenciar na obtenção de mais de um vínculo empregatício para por parte do trabalhador, porém causando excesso de sobrecarga, estresse e impacto na qualidade de vida, bem como, em muitos casos, adoecimento e afastamento das funções laborais (CARVALHO, et al. 20ı; ROCHA, 2019; PIMENTA, 2020)

Sendo importante mencionar que o enfermeiro possui o papel de líder na assistência, gerência e educação em saúde e é preciso que esse papel de liderança esteja bem claro dentro da equipe de enfermagem, para que seja possível prestar assistência de qualidade ao usuário. De forma a auxiliar também na concretude de valores e pensamentos da organização, visando atingir metas e objetivos de forma eficaz. (FERRO, et al. 2018). 


\section{ASSOCIADO AO PROFISSIONAL DE ENFERMAGEM}

Os aspectos intrínsecos ao profissional de enfermagem foram poucos avaliados nos artigos, ora objetos de estudo. Em seis deles ressaltou que o absenteísmo individual dar-se por motivos familiares, seja para realizar acompanhamento médico e/ou cuidados com filhos. Tais dados são motivados pelo fato de que no ambiente laboral de saúde, a absorção de mão de obra feminina é significativa, chegando a corresponder a taxa de $75 \%$ dos profissionais empregados nos estabelecimentos de saúde (LUCCA E RODRIGUES, 2015).

Desse parâmetro, advém a informação de que o absenteísmo é predominante ocasionado pelas mulheres. Sobre isso, um estudo realizado em um hospital de médio porte, evidenciou que o gênero feminino foi responsável por $81,4 \%$ dos afastamentos do trabalho (LUCCA E RODRIGUES, 2015).

Assim, considera-se que a maioria dos profissionais de enfermagem são mulheres e, por sua vez, além do trabalho cabe a elas, muitas vezes, liderarem com a responsabilidade que foge do contexto laboral, como a responsabilidade pelos cuidados dos filhos e afazeres domésticos. Tal fato reverbera que a dimensão psicossocial da duplicidade de papéis pode contribuir para a incidência das ocorrências relativas a ausência do trabalho (PIMENTA, et al. 2020).

Ainda nesse sentido, Murcho e Jesus (2014) abordam as causas relacionadas as ausência ao trabalho no aspecto individual como derivadas das necessidade dos profissionais de resolver assuntos burocráticos pessoais/familiares inadiáveis (a exemplo de finanças, bancos, escola), acompanhamento dos filhos, ou em casos de doença, acidentes e outros

problemas de saúde pessoais ou familiares, e cita até mesmo a realização de atividades de lazer que não podem ser realizadas durante as férias ou folgas.

É importante salientar a acentuada sobrecarga sofrida pelo grupo de mulheres. Segundo Ferreira et al (20II), a taxa de 80\% das ausências ao trabalho relatadas pelas mulheres decorrem da necessidade de cuidar dos filhos e da precariedade da estrutura doméstica por não ter com quem deixá-lo, principalmente quando eles adoecem. 
Assim Sancinetti et al (20II) corrobora ao frisar que o trabalho em turnos traz consequências importantes e prejudiciais a qualidade de vida do grupo feminino, especialmente quanto a dupla jornada de trabalho e pouco descanso após o turno, por ter que assumir os encargos domésticos e o cuidado aos filhos. Sendo esse um dos motivos pelos quais adoecem mais frequentemente e faltam mais ao trabalho" (FERREIRA, et al. 20II)

\section{CONSEQUENNCIAS DO ABSENTEÍSMO ENTRE OS PROFISSIONAIS DE ENFERMAGEM}

Ao que se refere às consequências geradas pela ausência do profissional no ambiente laboral, MARTINATO et al (20I0) entende o fenômeno como um fator causador de problemas, principalmente para a equipe de enfermagem. Verificando-se, com o absenteísmo, a variedade de consequências negativas em dimensão subjetiva dos trabalhadores (FERREIRA, et al. 2oII).

Extraiu-se dos artigos que a ausência dos profissionais afeta a organização do serviço, gera insatisfação e sobrecarga entre os presentes e compromete a qualidade da assistência prestada ao paciente. No contexto da sobrecarga da sobrecarga dos colaboradores presentes, acaba por se exigir deles o ritmo acelerado no realização das obrigações e responsabilidade à volume maior de trabalho derivado do processo de cuidar. (FAKIH, et al. 2012).

Neste sentido, a maioria dos estudos identificaram justamente o supramencionado, onde os profissionais costumam trabalhar o dobro ou ainda ou triplo do que já laboram normalmente para conseguir desempenhar também os encargos do colega ausente, assumindo um número maior de pacientes, afazeres e, consequentemente, maior carga de trabalho (MARTINATO, et al. 2010; LIMA, 2014; PERES, 2016).

Assim corrobora UMANN et al. (20II), revelando que as consequências do absenteísmo estão associadas a queda na qualidade da assistência, sobrecarga de atividades, falta de motivação do profissional ativo, risco na saúde do trabalhador comprometido e aumento dos custos financeiros despendidos com horas extras.

Não obstante, MARTINATO et al (2010) salienta que a sobrecarga poderá prejudicar a saúde do profissional presente no ambiente laboral causando do desgaste físico, 
psicológico, social ao espiritual e como consequência o adoecimento. Nesse mesmo sentido, os artigos citam o fator da sobrecarga a equipe como uma das principaias consequênciais geradas pelo fenômeno do absenteísmo.

Ademais, quanto maior a jornada de trabalho no ambiente hospitalar, maior é a exposição às cargas e riscos inerentes à profissão. Dessa forma, os profissionais de enfermagem são mais vulneráveis ao adoecimento, apresentando perfis diferenciados da população em geral, pois se encontram mais propensos a adoecer ou morrer por causas relacionadas ao trabalho e pela exposição inerente à atividade laboral (MACHADO et al, 2014; LIMA, 2014).

De outro modo, as consequências das faltas também atingem as ações direcionadas ao cuidado ao paciente, ao estar exigindo, daqueles que estão presentes, agilidade na execução de um número superior de tarefas. Assim, propiciando maior desgaste e dificuldade em atender os anseios dos clientes (SILVA, et al, 2018).

Diante das consequências geradas pelo absenteísmo de um profissional de enfermagem, entende-se que esse cenário também contribui para a elevação dos indices já existentes, ainda mais quando "as instituições hospitalares normalmente focam a sua prioridade no atendimento ao paciente, muitas vezes se esquecendo da saúde dos profissionais que executam o trabalho e estão ali presentes no ambiente laboral" (MARQUES et al, 2015). Assim sendo, necessário que se faça um reajuste com enfoque também no trabalhador e a reconhecimento da essencialidade de seu serviços.

\section{CONSIDERAÇÕES FINAIS}

A presente pesquisa permitiu identificar algumas das causas geradoras do absenteísmo, bem como suas consequências. Para tanto, foi feita uma análise por intermédio das contribuições cientificas sobre temática, donde sobreveio o entendimento da etiologia do fenômeno como de caráter multifatorial, assim, sendo aquele que pode ter múltiplas causas. Partindo desse pressuposto, primou por citar as causas mais recorrentes do absenteísmo entre os trabalhadores de enfermagem e classificar, com fim meramente didático, a ocorrência do fenômeno quando derivado do ambiente laboral ou organizacional, da relação interpessoal sendo de equipe ou liderança e o absenteísmo proveniente da voluntariedade do colaborador de enfermagem. 
Assim sendo, quando no contexto de trabalho observou a influência significativa que o mesmo possui para a eficiência e produtividade do trabalhador de enfermagem, tal como na sua saúde e qualidade de vida. Notou-se que ausência de suporte mínimos para exercícios da atividade profissional compromete o desempenho profissional e pode ocasionar diversos estresses que, por sua vez, chegam na máxima do afastamento pelo desencadeamento de doenças ocupacionais. Motivo pelo qual se vislumbra a essencialidade em ofertar suprimentos necessários e buscar a promoção de programas assistenciais, pautados no entendimento das necessidades daqueles que integram o ambiente hospitalar.

Não obstante, quando na relação interpessoal entre equipe e liderança, compreendeuse que a ausência de comunicação e diálogos saudáveis são motivos causadores do absenteísmo, assim como falta de remuneração e reconhecimento devido. Nesse ponto, em decorrência desses fatores tem-se a acentuada desmotivação do grupo que podem leva-los a falta de identificação ou propósito para exercício da profissão. Há também a sobrecarga que alguns profissionais despejam em detrimento de outros e o acúmulo de funções que ocasionam em desgaste. Sendo importante que seja feito um investimento de tempo e gerencial para o incentivo de uma postura ativa de todos os colaboradores.

Quanto aos aspectos geradores do absenteísmo pelo próprio individuo, vislumbrouse que se trata de algo pouco debatido nos estudos sobre a temática. Apesar disso, nesse aspecto, observou-se que a maioria dos integrantes dos quadros de trabalhadores de enfermagem são identificados como do perfil feminino, e por esse motivo é recorrente que se tenha a duplicidade de papéis e maior exaustão levando ao absenteísmo, considerando ainda que fazem parte desse grupo, em regra, mães que além de cumprirem com seu papel profissional deve também atentar-se aos deveres domésticos e familiares.

Ao final, observou-se que as consequências do absenteísmo afligem principalmente os trabalhadores de enfermagem responsáveis por suceder o colaborador faltante, causando ainda mais desgastes. Não só isso, culminando na afetação da organização hospitalar como um todo, e seu regular funcionamento na prestação de assistência aos pacientes. Assim, comprometendo todas as figuras que integram o processo de cuidar.

Com isso, vale ressaltar a importância da assunto no sentido de apontar a problemática e incentivar a busca por ferramentas e estratégias que possibilitam serem mais 
eficientes e combativas quanto ao absenteísmo. Ainda, primando pela saúde e resguardo do profissional para que esse exerça o oficio em que foi designado com qualidade e devida assistência aos seus pacientes. Destaca-se que esse estudo não visou esgotar o assunto, tampouco abordar todas as variantes que emergem do afastamento laboral.

Dessa forma, espera-se subsidiar a discussão e a análise da questão, tal como os aspectos primordiais que permeiam a ocorrência do absenteísmo, a fim de que sejam feitas propostas que corroboram para uma modificação no processo de trabalho e políticas de gestão existentes, assim como na promoção da saúde e amparo aos colaboradores, contribuindo para sua maior satisfação no trabalho e compromisso com a organização.

\section{REFERÊNCIAS}

AZEVEDO, Jaiana Nerak Lima; SILVA, Roberta Ferreira; DE MACÊDO, Tassia Teles Santana. Principais causas de absenteísmo na equipe de enfermagem: revisão bibliográfica. Revista Enfermagem Contemporânea, v. 8, n. I, p. 8o-86, 2019.

BREY, Christiane et al. O absenteísmo entre os trabalhadores de saúde de um hospital público do sul do Brasil. Revista de Enfermagem do Centro-Oeste Mineiro, v. 7, 2017.

BRITO, Taiana Borges; SOUSA, Maria do Socorro das Chagas; RODRIGUES, Tatyanne Silva. Síndrome de Burnout: Estratégias de prevenção e tratamento nos profissionais de enfermagem. Rev. UNINGÁ, Maringá, v. 56. n.2, 2019, p. 113-122.

BRASIL, COFEN. Conselho Federal de Enfermagem. Brasilia, DF. 1986 - Disponível: < http://www.cofen.gov.br/lei-n-749886-de-25-de-junho-de-1986_4161.html>. Acesso em I2 de março de 202I.

CARVALHO, Luciana Souza Freitas et al. Motivos de afastamento por licença de saúde dos trabalhadores de enfermagem. Ciência, Cuidado e Saúde, v. 9, n. I, p. 6o-66, 2010.

CHIAVENATTO, I. Gestão de pessoas. O novo papel dos recursos humanos nas organizações. 4. ed. São Paulo: Manole, 2014.

DEJOURS, Christophe. Psicodinâmica do trabalho e teoria da sedução. Psicologia em Estudo, v. 17, n. 3, p.363-371, 2012. 
FAKIH, Flávio Trevisani; TANAKA, Luiza Hiromi; CARMAGNANI, Maria Isabel Sampaio. Ausencias de los colaboradores de enfermería del servicio de emergencia de un hospital universitario. Acta Paulista de Enfermagem, v. 25, n. 3, p. 378-385, 2012.

FELDHAUS, Carine et al. Associação entre carga de trabalho e absenteísmo de profissionais de enfermagem de nível médio. Texto \& Contexto-Enfermagem, v. 28, 2019.

FERRO, Denise et al. Absenteísmo na equipe de enfermagem em serviços de emergência: implicações na assistência. Acta Paulista de Enfermagem, v. 31, n. 4, p. 399-408, 2018.

FERREIRA, Edeilson Vicente et al. Absenteísmo dos trabalhadores de enfermagem em um Hospital Universitário do Estado de Pernambuco. Revista da Rede de Enfermagem do Nordeste, v. 12, n. 4, p. 742-749, 2011.

KURCGANT, Paulina et al. Absenteísmo do pessoal de enfermagem: decisões e ações de enfermeiros gerentes. Revista da Escola de Enfermagem da USP, v. 49, p. 35-4I, 2015.

LIMA, Leticia Trindade et al. Absenteísmo na equipe de enfermagem no ambiente hospitalar. Enfermería Global, v. 13, n. 4, p. 138-155, 2014.

LUCCA, Sergio Roberto de; RODRIGUES, Marcelo Scapari Dutra. Absenteísmo dos profissionais de enfermagem de um hospital universitário do estado de São Paulo, Brasil.

Rev Bras Med Trab, v. 13, n. 2, p. 76-82, 2015.

MAGALHÃES, Nilma Alves Cavalcante et al. O absenteísmo entre trabalhadores de enfermagem no contexto hospitalar. Rev enferm UERJ, v. 19, n. 2, p. 224-30, 2011.

MARQUES, Divina de Oliveira et al. O absenteísmo-doença da equipe de enfermagem de um hospital universitário. Revista Brasileira de Enfermagem, v. 68, n. 5, p. 876-882, 2015.

MARTINATO, Michele Cristiene Nachtigall Barboza et al. Absentismo en enfermería: una revisión integrativa. Revista Gaúcha de Enfermagem, v. 31, n. I, p. 160-166, 2010.

MENDES, Karina Dal Sasso; SILVEIRA, Renata Cristina de Campos Pereira; GALVAO, Cristina Maria. Uso De Gerenciador De Referências Bibliográficas Na Seleção Dos Estudos Primários Em Revisão Integrativa. enferm., Florianópolis, v. 28, 2019. 
MININEL, Vivian Aline et al. Cargas de trabalho, processos de desgaste e absenteísmodoença em enfermagem I. Revista Latino-Americana de Enfermagem, v. 2I, p. I290-I297, 2013. MURCHO, Nuno AC; JESUS, Saul Neves. Absenteísmo no trabalho. Novas medidas do comportamento organizacional: ferramentas de diagnóstico e de gestão. Porto Alegre: Artmed, p. 15-23, 2014 .

PERES, Renata Bastos. Absenteísmo de técnicos de enfermagem em uma unidade de urgência e emergência de um hospital universitário. 2016.

PIMENTA, Cláudia Jeane Lopes et al. Condições de saúde e características do trabalho de enfermeiros de um hospital universitário. 2020.

PORTO, Ricardo Bersch. ABSENTEÍSMO: causas e consequências na organização. Maiêutica-Estudos Contemporâneos em Gestão Organizacional, v. 4, n. I, 2016.

REZENDE, Roseli; BORGES, Najla Moreira Amaral; FROTA, Oleci Pereira. Síndrome de Burnout e absenteísmo em enfermeiros no contexto hospitalar: revisão integrativa da literatura brasileira. Comun. ciênc. saúde, p. 243-252, 2012.

ROCHA, Felipe Pereira et al. Absenteísmo-doença entre profissionais de saúde de um hospital público estadual em São Paulo. Revista Brasileira de Medicina do Trabalho, v. 17, n. 3, p. 355-362, 2019.

SANCINETTI, Tânia Regina et al. Taxa de absenteísmo da equipe de enfermagem como indicador de gestão de pessoas. Revista da Escola de Enfermagem da USP, v. 45, n. 4, p. 1007IOI2, 2011.

SILVA, Jussara Aparecida Furlan et al. O profissional de enfermagem e sua percepção sobre absenteísmo. Revista Eletrônica de Enfermagem, v. 20, 2018.

SOBRAL, Renata Cristina. Fatores psicossociais de risco no trabalho e a síndrome de burnout. Tese (doutorado) - Universidade Estadual de Campinas, Faculdade de Ciências Médicas, Campinas, SP, 2015. II9 p.

UMANN, Juliane et al. Absenteísmo na equipe de enfermagem no contexto hospitalar. 
Ciência, Cuidado e Saúde, v. Io, n. I, p. I84-19o, 2011. 